Izabela Derda (iD) https://orcid.org/0000-0003-4223-4692

Erasmus School of History, Culture and Communication, Rotterdam

e-mail: izabela.derda@escch.eur.nl

\title{
Advertising Content Acquisition through Crowdsourcing Platforms. Case Study'
}

\begin{abstract}
Although crowdsourcing is no longer a new phenomenon, it is constantly evolving and influencing the formation of exchange mechanisms and relations between their participants. To the advertising and marketing industries, which need the perpetual influx of fresh and unconventional ideas, it has become one of the ways to acquire innovative solutions and (often) the content produced at costs below the market price level. Crowdsourcing has also become a tool to get consumers involved and build their brand loyalty. This paper analyses how brands use crowdsourcing platforms to acquire advertising content and sheds light on some of the associated problems.
\end{abstract}

Keywords: crowdsourcing, participation, advertising, media production, branded content.

Słowa kluczowe: crowdsourcing, partycypacja, reklama, produkcja mediów, branded content.

When seeking the possibilities of engaging consumers, brands invite them to enter deeper into their world. They open themselves to partnerships on new fields, using blurred boundaries and reversed roles of creators and recipients. To this end, they increasingly often do not limit themselves in the idea generation process exclusively to using their own internal resources and working with business partners, but they assume that valuable ideas and innovations can come from consumers and non-professionals, according to the concept of open innovation [Malinowski 2015: 47].

1 This article was prepared on the basis of parts of the unpublished doctoral dissertation entitled Advertisement at the Dawn of the Post-network Era. Branded Content, a Case Study. SWPS University of Social Sciences and Humanities 2017. 
Using the potential of digital technologies and online communities, they contract tasks to specific groups of network users in the hope of earning innovative and creative ideas in the process of crowdsourcing ${ }^{2}$. This mechanism is also used to build relationships with recipients, emphasize the meaning of consumer opinion, and earn advertising content.

The objective of this article is to analyse the process of earning content by brands, as well as to understand the mechanisms that govern it. The analysis takes into consideration the multilateral nature, replaceability and complexity of the process, focusing on objectives and motivations of both parties - content-earning advertisers and content-providing recipients. The study involves an analysis of selected campaigns and examples of using grassroots creativity, as well as the operation of platforms concentrating creative amateurs, amateurs who wish to become professionals, and freelancing professionals, engaged in the creation or cooperation in the execution of professional advertisement campaigns initiated and financed by brands.

This analysis constitutes a part of a wider study concerning the phenomenon of branded content ${ }^{3}$, analysed as a complex process taking place between the brand, consumers, medium and technology.

\section{Crowdsourcing and participation}

The processes of media democratization and development of the user content creation culture have contributed to the creation of a new type of media users: prosum$\mathrm{ers}^{4}$, i.e. producers-consumers operating at the community level, and along with them of projects taking advantage of collective intelligence, such as Wikipedia and open-source software. This movement is called crowdsourcing, and (according to some researchers) it positively impacts social relationships thanks to the empowerment of the recipient's position in relationships with corporations [cf. Jenkins 2007; Bruns 2008]. From this perspective, the theory of participation understood as the commonly available engagement of recipients in culture by receiving, interpreting and deconstructing media texts, as well as the act of creation and appropriation, has found its place in the cultural studies theory [Schäfer 2011: 148]. However, Mirko Tobias Schäfer notices that this perception is ideologically loaded and assumes that participation is a deliberate and conscious process involving activities

${ }^{2}$ A participatory process taking place in the online environment. Its name combines the words crowd and outsourcing, meaning contracting works "outside" one's own organization [Howe 2006].

${ }^{3}$ Advertisement at the Dawn of the Post-network Era. Branded Content, a Case Study.

${ }^{4}$ Axel Bruns invented the term produsage (a portmanteau of production and usage) to label new practices intended to link community members who produce contents and are simultaneously users and producers [Bruns 2008, cited in Schäfer 2011: 148]. 
of users declaring cultural freedom from the culture industry, which romanticizes the phenomenon of participation too much [Schäfer 2011: 148].

On the flip side of Jenkins's vision of media as a truly democratic environment there is a dystopian perspective presenting interactivity as a form of labour and digital exploitation of communities by corporations [cf. Andrejevic 2007; Dijck 2011]. This exploitation primarily consists in the asymmetric relation of power that favours big business at the expense of prosumers who actively provide data, ideas, contents, etc. Furthermore, prosumption can provide content creators with the illusory vision of freedom, possession of influence and validation [Kopeć 2014: 159]. John Caldwell also indicated that $\mathrm{UGC}^{5}$ changed not only the relationships between senders and recipients, but also corporate production practices, and user-generated content began to constitute parts of broadcast as well as tools of promotion [Caldwell 2011: 283-284].

Users becoming a labour force acting to the benefit of corporations participate in a type of labour outsourcing [cf. Caldwell 2011; Andrejevic 2003]. Thanks to this, according to Caldwell, users can participate in the production of media content (in this case - advertising) without remuneration or other benefits and without any employment title. They are not organized in any way neither and, therefore, cannot demand their rights be respected [Caldwell, 2011: 286]. In practice, however, network users are remunerated for their work for brands, although problems and doubts arise here as well ${ }^{6}$.

The aforementioned relationships also concern crowdsourcing used in the advertising practice. Brands and their agencies engage the crowd to execute creative tasks: from evaluating the brand's ideas, through earning concepts, to production of complex advertising contents [Brabham 2010]. This deep engagement of users, liberation of content from the medium, as well as its fluidity resulted not only in the redefinition of the brand-consumer relationship, but also in a new perspective on media planning in campaigns. The advertising industry began to accept a new categorization of media, thus previously used categories such as television, press, radio, outdoor, cinema or the internet are (in certain environments) being displaced by paid, own and earned media [Turow 2014: 133]. The latter have the greatest meaning in the context of participation. We can speak of earned media in situations where products or contents offered by a brand result in increased publicity for that brand without utilizing traditional advertising budgets [Edelman, Salsberg 2010: 3]. They can include both unpaid mentions in traditional media (e.g. product reviews) as well as contents present in network users' own media. These can be, for example, how-to or unboxing videos and entries, reviews and opinions on blogs and internet forums, remakes, parodies, or even shares of brand-originated content, or content earned in crowdsourcing processes.

\footnotetext{
${ }^{5}$ User-Generated Content.

${ }^{6} \mathrm{I}$ address this in the study part.
} 


\section{Crowdsourcing of advertising content. "Sprite. Let the truth refresh you"}

One example is Sprite's effort in Poland conducted as part of the Sprite. Let the truth refresh you campaign in 2013. The objective of the campaign was to promote emotional values of the brand among the Millennial Generation. Its idea was to engage internet users by inspiring them to discover the "refreshing truth"; the activities focused on the slogan and hashtag \#thisisthetruth. One of the parts involved a competition to create a TV commercial ${ }^{7}$ which reflects the slogan "Let the truth refresh you" the best. The competition was aimed at all recipients, in particular at the online creative community and young consumers. Its objective, in addition to the promotion of the slogan and potential earning of creative content to use in the campaign, was to engage recipients in the brand's world at the competition stage and after its conclusion (by further circulation of the earned content).

\section{"Crowd." meaning who?}

Sprite's competition was executed in partnership with MillionYou, a crowdsourcing agency founded in 2007. According to its owners, their business objective is to enable brands to co-create with communities, and their offer includes handling crowdsourcing in new product creation processes, communication strategy, videos, scripts, images, and even city development plans. By concentrating over 27,000 internet creators around its own platform, including amateurs, semi-professionals and freelancers from the creative industry, and thanks to numerous partnerships, including with film schools, as well as to the techniques learned over the years of skilful engagement and motivation of communities and managing them in projects [Slezkin 2016], MillionYou declares the ability to reach the target group specified by the client and earn a wide range of specified content.

The creative community of MillionYou includes primarily people aged 20-25, mainly from Poland. They represent various levels of skills related to filming, screenwriting, copywriting and graphic design. They include mainly enthusiasts and amateurs who wish to perfect their skills or who simply have interesting ideas they want to share with others [Kasprzycki-Rosikon personal communication, January 18,2016$]$. Creator recruitment is mainly based on working with film schools as well as high schools. Each video competition of MillionYou is also promoted in social media, sometimes additionally by larger activities - e.g. by film festivals and other steps agreed upon with the client. Clients often conduct support activities

7 The competition intended to select the winning video that could be used by the brand in a regular TV campaign. The rules reserved such possibility; however, it was not guaranteed and depended on the quality of earned content. 
on their own, occasionally with the participation of their media house or agency handling online campaigns.

Attractive monetary prizes and other incentives motivate creators to participate. Very often beginning filmmakers, including those from small towns, working for local clients, gladly build their portfolio using competition entries for known domestic or international brands. They are interested in gaining experience working for "real" clients and obtaining credentials in the form of diplomas issued by MillionYou to winners and nominees. Furthermore, wins and nominations enable creators to build their reputation as part of the MillionYou platform and be promoted to the so-called "PRO community" (a closed community of professional creators who are recruited) and receive direct contracts as part of crowdsourcing projects without the mechanism of competition [Kasprzycki-Rosikon personal communication, January 18, 2016].

\section{Content earning process}

In its activities, the Sprite brand decided to direct messages to both creative online communities and the group of young recipients in general. Therefore, in addition to the activities as part of the MillionYou community, the brand decided to promote the competition more widely and to launch a campaign in mass media.

Competition activities were divided into three phases:

Phase 1 (Preparatory) - preparing to launch the competition involving: preparing a creative brief structured in such a manner as to be attractive to potential participants, to invigorate creativity and encourage to participate; creating a website containing information about the competition, rules, promotional videos, and after the conclusion of the competition - its results; preparing visuals; legal consultations, including preparation of the rules.

Guidelines for creators were very limited and did not resemble a traditional advertising brief. Internet users only received the information that the submitted video should last 18 seconds and show situations, people or behaviours that are, in the authors' eyes, inauthentic and insincere (2013 competition rules). At this stage it was also determined that the total value of prizes will amount to PLN 37,000 in cash and will be split between 10 nominees (each will receive PLN 1,000). Among the nominees, the jury will select three winners who will additionally receive PLN 9,000 . Moreover, each of the three videos receiving the main prize had the chance of being broadcast on the television as part of Sprite's regular advertising campaign.

Phase 2 (Promotion and competition start) - beginning the competition communication, support, earning content. 
Competition communication focused on two objectives and was aimed at two target groups. The first objective was to earn valuable video content, which is why the first target group included creators - recruited and engaged from the community concentrated around MillionYou, film school students, users of internet forums dedicated to video content creation, and by advertisements published on online portals that deal with this topic.

The second objective was to interest the wide group of recipients as well as to engage consumers and amateurs in competition activities. This resulted not only in the increased awareness of the communicated brand values, but also in earning content created by consumers who had smaller chances to compete with videos created by creative communities, and enabled the consumers preparing submissions to better learn the values communicated by the brand and engage in its activities. This also increased the total number of submissions.

To promote the competition, commercials were created showing how potential submissions could look while meeting the requirements of the competition brief. They presented how competition videos can expose artificial and false behaviours and situations. Videos promoting the competition were not very complex and used simple production and staging means (made in one shot using a single camera with a small number of actors, background limited to natural locations, with simple, easily accessible props and costumes), which is why they constituted a guide and a reference point for creators wishing to submit their works. Teasers were broadcast on television and online so as to, in addition to potential participants recruited from the community concentrated around MillionYou and its partners, engage amateur participants and intrigue the mass public.

During the second stage participants, through the MillionYou agency, could take advantage of the technical support regarding submissions, and primarily of the legal consultation with respect to copyrights to the elements of the video, e.g. music.

Nominees and winners were also selected during this stage. The agency pre-moderated and preselected all submissions. Ultimately, the jury selected 10 videos from 208 submissions and the three winners. The Grand Prix, the amount of PLN 9,000 and broadcasting the video on television, was awarded to the video made by two filmmakers, Paweł Zawadzki and Damian Daniłowicz, who created it under the name Pawian Pictures.

The winning video shows a scene taking place in an elegant restaurant. The customer sniffs the beverage in his glass and, speaking French, with the expression of a connoisseur, complements its bouquet, tastes it and tries to guess the name and vintage of the wine - Château Valons, 1976. The waiter answers (also in French, although his looks suggest Indian ancestry) to correct him and says that it's Sprite, 2013. The following dialogue takes place in Polish: 
"Frenchman": "No, you're kidding me." (The music in the background fades out) "Waiter": "Why, kind sir! Kid you I not!"

In subsequent shots, the protagonists first "clink" the bottles of Sprite in toast, then pour champagne on themselves in a manner characteristic of the winners of a motorsport competition. We hear the voiceover of the waiter: "Sprite. Let the truth refresh you", and we see the image from the regular Sprite campaign.

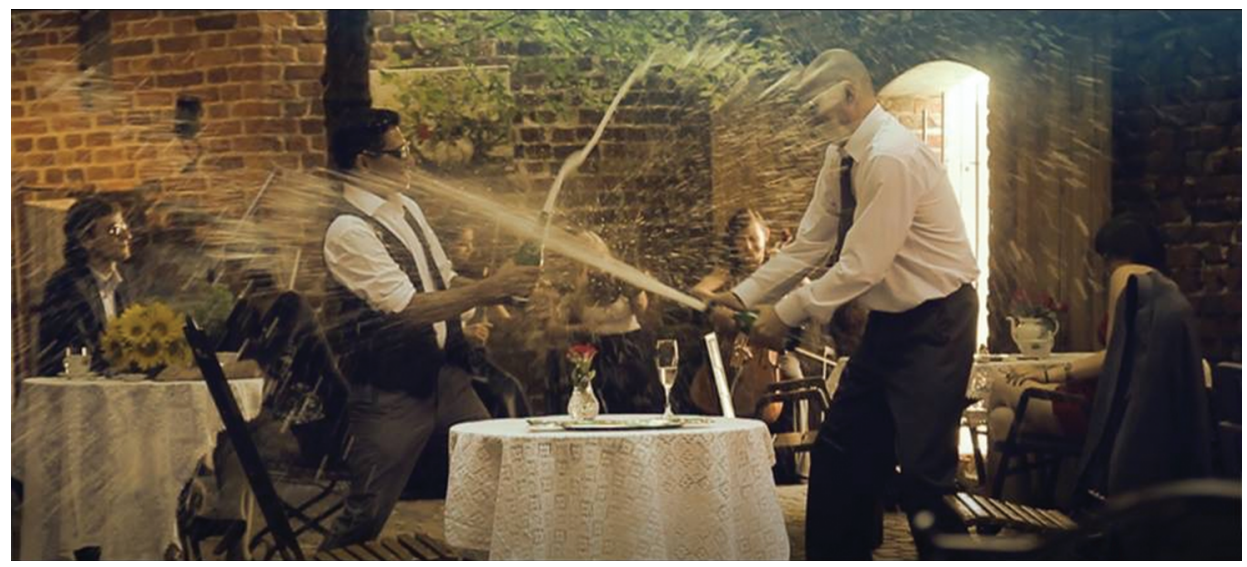

Figure 1.

Shot from the winning video of the competition "Sprite. Let the truth refresh you" [https://www.youtube.com/ watch?v=sgI66YwHE4Y, access: 20.01.2019]

It is worth noticing that the broadcast video was created, produced and submitted for the competition by Pawian Pictures. However, among MillionYou activities, we can also find such videos where the marketer decided to use an idea for the video but - for the purposes of the campaign - produced it in professional conditions. An example of such situation is presented on figure 2 . 

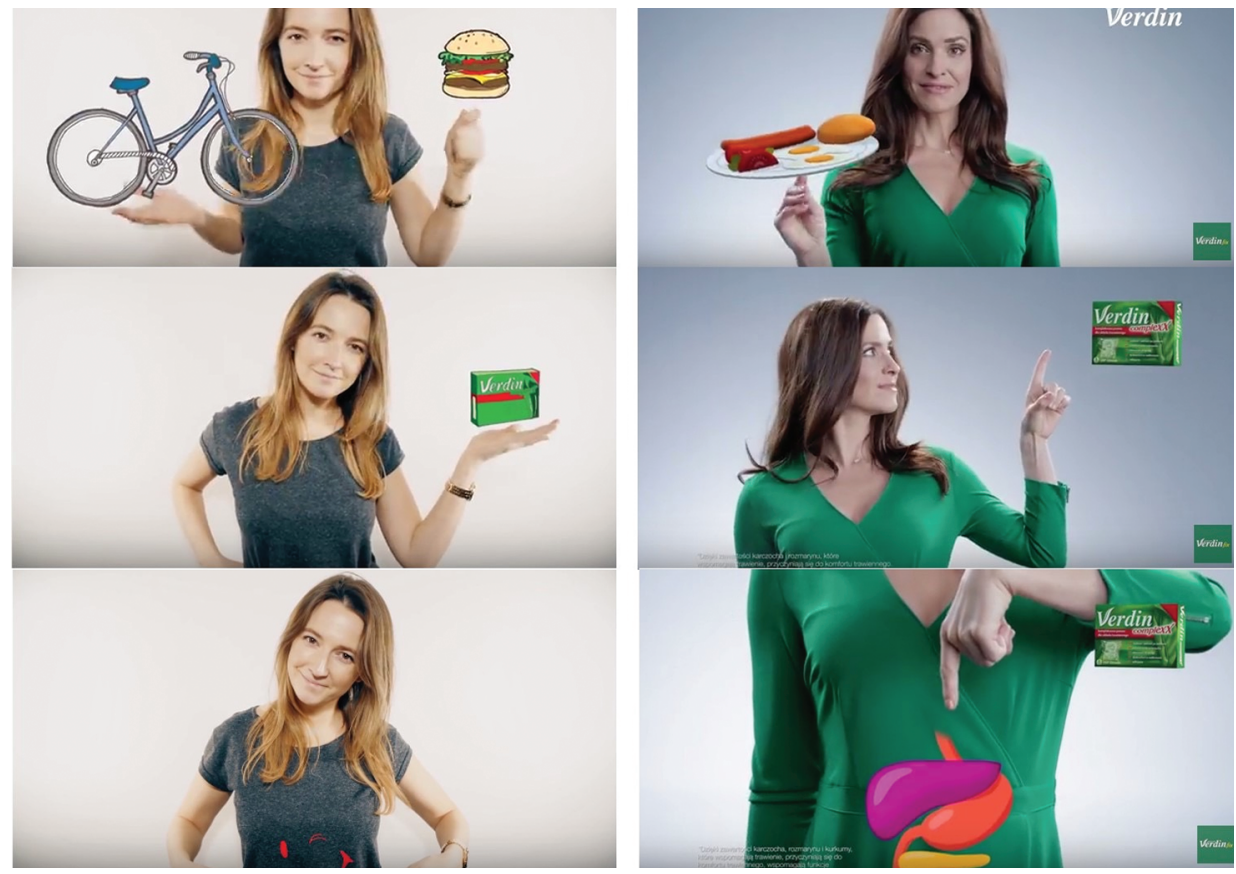

Figure 2.

Video for the Verdin brand: on the left, the amateur version submitted for the competition, on the right, the professional version created on the basis of the competition submission [video on the left: https://www.youtube. com/watch?v=ze775ildjVE, access: 20.01.2019, video on the right: https://www.youtube.com/watch?v=tHZG5jVSl0, access: 20.01.2019]

\section{Phase 3 (Application)}

In the final phase, the focus was on the post-competition communication using earned content. Since they were made by internet users, nominated and winning videos organically generated over two million views in total within three months of publication, mainly thanks to the social networks of the users. The winning video was broadcast on television and online as part of the Sprite brand campaign (thanks to its high quality, it was also used on other European markets), which enabled the brand to generate additional noise in relation to the activity, the value of which also constituted a certain media analogue.

During the entire process, the Sprite brand decided to limit the risk posed by giving the initiative into the hands of the community. The submitted videos were sent to the MillionYou agency and pre-moderated, while the winners were selected by the jury appointed by the client and the agency. The mechanism of selecting winners by online voting was not used (risks of such solutions are mentioned later). 
Each phase of the process was fully controlled by the brand and did not provoke the presence of unauthorized activities in the process.

\section{Manaģing communities}

The idea of a sharing economy and thus crowdsourcing, which is one, is based on the assumption that the world is full of unused resources [Kasprzycki-Rosikon personal communication, January 18, 2016]. When earning videos, graphic designs, concepts, communications or other advertising forms, human labour and talent are such resources. Critics indicate that, like in the case of wider participation, this model lets media conglomerates and corporations gain excessive benefits from free (or low-paid) labour thanks to the flexible economy of the digital media [cf. Andrejevic 2007; Dijck 2011; Caldwell 2008, 2011; Brabham 2010]. They indicate that even when assuming gratification for the process participants, remuneration (understood not just as cash or in-kind prizes, but also discount vouchers, access to special prices or benefits resulting from making a product or service better, and so on) for the labour in projects executed using online communities is out of proportion to benefits reaped by corporations. In a traditional process, tasks delegated to the crowd would have to be executed by internal employees, contracted to business partners or subcontractors for a fee significantly exceeding profits of process users. On the other hand, the proponents, like in all actions of the participation culture, indicate the voluntary nature of the participation in processes, the growing awareness of network users, and access to new resources and experiences.

Winners of the competition organized by Sprite, authors from Pawian Pictures, i.e. Damian Daniłowicz and Paweł Zawadzki, emphasize that they do not feel like they were exploited by the brand and indicate the benefits resulting from winning. According to them, they were semi-professionals during their participation in the competition. The first person - Damian Daniłowicz - is a graduate of philosophy and postgraduate studies in Film and Television Production, while the second person - Paweł Zawadzki - is a graduate of Artistic Education at the Faculty of Fine Arts. Together, they made a dozen or so amateur and semi-professional commercials for various competitions. They admit that they participated in the Sprite campaign primarily due to the brand and the monetary prize. The potential prestige and promotion in case their commercial was broadcasted on television were also important.

The production of their video cost approximately PLN 400-500 and included three days of pre-production and two days of shooting and editing. The creators are aware of the rift between their budget and rates collected by professionals:

Of course we are aware of the fact that a regular commercial for the Sprite brand would cost way more than the value of prizes. However, due to the promotion and a kind of prestige, we 
are pleased that the video became the official commercial of the campaign. We didn't receive additional profits for the video being used in the campaign. It was a competition and the rules were clear- we knew what we were signing for [Pawian Pictures personal communication, January 24, 2016].

They also emphasize that they definitely profited from their participation in the competition with respect to the promotion and development of their advertising career:

The commercial was recognizable and broadcast practically everywhere. People knew it and liked it. Our "kid you I not" entered the vernacular for a while - we heard this joke many times at pubs, buses, etc. This video in the portfolio helped us in talks about further contracts. The reference point was that, with a new contact, we only had to show two seconds of the video for the interlocutor to recognize the commercial and want to work with us [Pawian Pictures personal communication, 2016].

Today they are professionals: Daniłowicz operates his own film production and advertisement-related business; Zawadzki works as an independent director and "creative". They admit that the stage of video competitions is behind them, at least domestically.

Nonetheless, the relationships between the "crowd" and the brand are not always as both parties wish. According to both the representatives of the MillionYou agency and the competition participants themselves, transparency and clearly specified rules of partnership are very important in this kind of cooperation. Participants must precisely know what is expected of them, what prizes are they competing for, and how their work may be used (on which platforms, over what period, where). Incompetent management of the crowdsourcing process, ignorance of mechanisms at play on the internet, nature of online communities, as well as all ambiguities and understatements can lead to misunderstandings and therefore waves of negative reactions and comments in the social media and the brand's image damage.

One example of such activity can be the campaign of Villa Fresh Italian Kitchen, a restaurant network in California. The brand asked the internet users to invent and vote on the name of the new product available in their offer - the apple-flavoured Mountain Dew beverage [owned by Pepsico Co.]. In effect, it received a list of vulgar and inappropriate name propositions that were the most popular among the internet users who voted for fun. It ultimately resulted in naming the new beverage simply Apple Mountain Dew and Pepsico distancing itself from the campaign of the restaurant network [Slezkin, 2016]. 


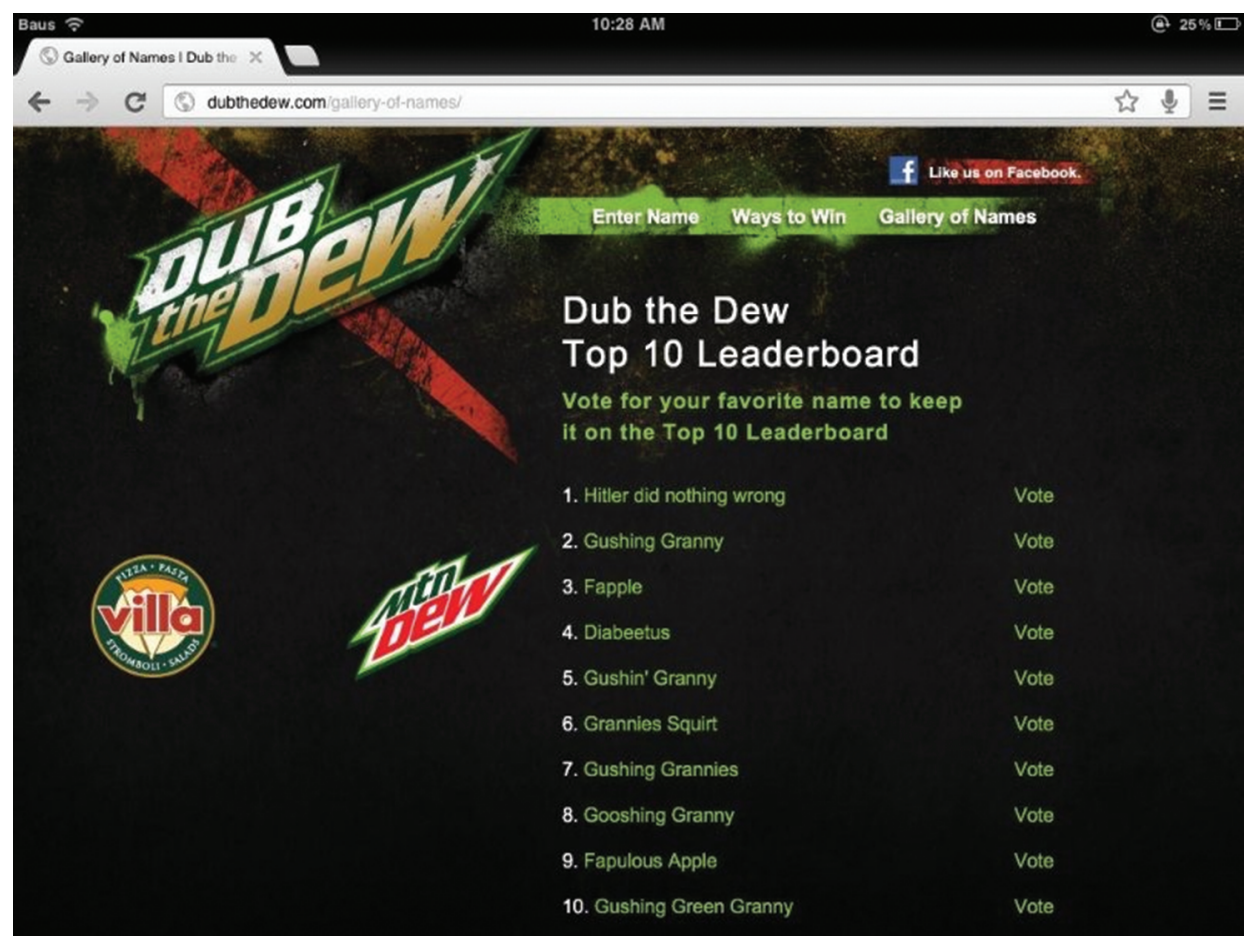

Figure 3.

Ranking of the most popular name propositions for the new beverage in the campaign of Villa Fresh Italian Kitchen [https://knowyourmeme.com/memes/events/dub-the-dew, access: 23.02.2019]

Another example might be the spontaneously arranged and completely failed crowdsourcing campaign of the GAP clothing brand. In 2010, after over 20 years, GAP decided to change its characteristic logo ${ }^{8}$. Just after introducing the new logo, the social media were flooded with the wave of critique for the new proposition. The brand thanked for the lively reactions and discussions and asked the internet users to send in their propositions. The internet users responded with an enormous number of designs that can be understood as parodies of the proposition of the new GAP logo. Websites like "Crap logo yourself" also began to appear online. The brand did not specify any conditions of the new logo competition, there was also no information about any gratification, which was met with an additional crushing wave of critique:

8 The GAP logo is a design element of many of the brand's products, which is why many loyal customers of this clothing manufacturer are attached to the traditional logo. 
I should let you know that I've also frequently shopped at your stores. You sell good stuff. But never in my experience has any of your employees offered me a free pair of pants because the ones I was wearing looked bad. I wouldn't expect them to. Their job is to sell me clothes. My job is to sell design - Mike Monteiro9 [idsgn.org 2010].

I firmly believe that crowd-sourcing and spec work is about designers giving their work away for free. But it is also about an abuse of power. The 'client' has it all. The designer has none. Unless, of course, we say no - Debbie Millman ${ }^{10}[$ idsgn. org 2010] ${ }^{11}$.

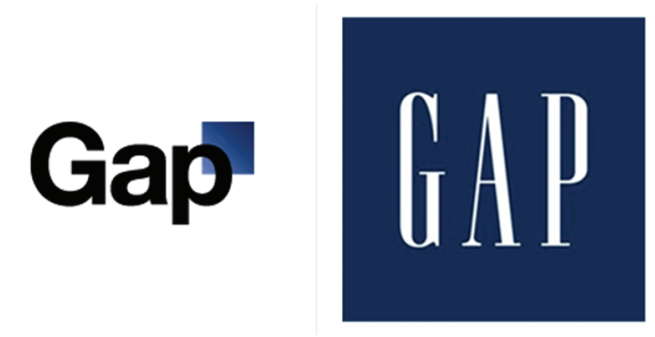

Figure 4.

On the left: the new logo proposed by the brand; on the right: the traditional GAP brand logo [money.cnn. com/2010/10/08/news/companies/gap_logo/index.htm, access: 22.02.2019]

Ultimately GAP returned to its old logo, withdrawing both from its proposition and the "competition" it organized. Costs borne by introducing the new logo, and thus the brand's losses, are estimated at around a hundred million dollars [brandfolder.com 2015].

The aforementioned examples show how planning and designing campaigns as well as understanding the online community, network user behaviours and skilful communication with them are important in the crowdsourcing process. Incompetent and inconsiderate use of crowdsourcing can not only not result in the intended effect but also expose the brand to ridicule and damage both its image and business.

9 Mike Monteiro, graphic designer, co-founder of Mule Design.

${ }^{10}$ Debbie Millman, president of the American Institute of Graphic Arts (AIGA).

${ }_{11}$ This situation reflects the critique of interactivity and participation as a digital exploitation of communities. The brand, pretending to care for the opinion of consumers, uses its position of power and exerts the will to use participation as a form of labour. 


\section{The brand-"crowd"-media relationship}

When analysing the Sprite campaign, it's difficult to say that the main motivation of the marketer was to generate savings and obtain the commercial for a small price. Naturally, if we compare expenses borne for prizes for the participants with production costs of a commercial made by a professional advertising agency and production house, we can have this impression. Nevertheless, when looking from a wider perspective, we should notice that the entire visual side of the competition (including the teaser campaign with commercials promoting the competition, the MillionYou ${ }^{12}$ agency service and costs of running the competition, broadcasting the winning content, PR services, delegating employees to handle the campaign) cost the brand probably many times more than the cost of a traditional thirty-second commercial. Furthermore, the brand could not assume that it will receive high-quality videos in the competition, with a reasonably brilliant punchline, reflecting the brand's philosophy and aesthetics, meeting technical requirements for a television broadcast, and could thus reduce its costs in the campaign that followed. Naturally, it increased its chances by engaging a crowdsourcing agency concentrating many talented creators around it; however, aware of the lack of a guarantee of earning content that satisfies the marketer, the rules stated that "the 3 best Videos will have the opportunity to become the official Sprite television campaign commercial"; therefore, such distinction was not guaranteed. According to Michał Slezkin from MillionYou:

By engaging the community in crowdsourcing projects, we are tackling the unknown in a sense. Despite planning the process down to the tiniest details, we cannot foresee the result and thus how the process will end. As project administrators, we are responsible for creating frameworks and rules, but at a certain moment we have to hand over the reins and trust the intuition of the "crowd" [Slezkin 2016].

It should be noticed that earning content was an indirect objective of the campaign and not the reason for doing it. In Sprite's competition, content is a side effect of activities focused on attracting the attention of and engaging young recipients in the brand communication, which sets them apart from crowdsourcing campaigns focused on earning fresh ideas and solving problems thanks to online communities. In this situation, the brand was both the content supplier - within the meaning of traditional advertising campaigns in the teaser phase of the competition (media push) - as well as its initiator (media pull). Prosumers inspired by the brand's initiative became producers of content constituting the core of the campaign. They were

12 According to the price list of 2016, it is a cost between PLN 75,000 and 150,000 depending on the selected package of services. 
also one of its carriers and distributors, next to the platform built by MillionYou and traditional paid fields of exploitation used to broadcast the winning video.

Thanks to the competition, the brand enabled the existence of numerous communication contexts on many platforms (traditional media, the internet, PR) as well as launched the chain of distribution of the selected contents through social networks and industry portals. User-created content allows the brand reach the social circles of the nominees and their friends, and contact people interested in the competition and/or participating in it. This way, the advertising content gained an additional field of free exploitation supported by recommendation.

Moreover, the rhetoric of the campaign was intended to attract the recipients by using the language and culture of the target group, but the campaign could simultaneously constitute for the brand a source of knowledge about consumers who informed it about their views on the world and their peers by exposing behaviours and situations they identified as dishonest. Thus, Sprite managed not only to build a reach for the campaign, earning the attention of a group of young internet users, which is difficult to get a hold of, but also to stand out as a reliable brand that understands its target group and listens to its voice.

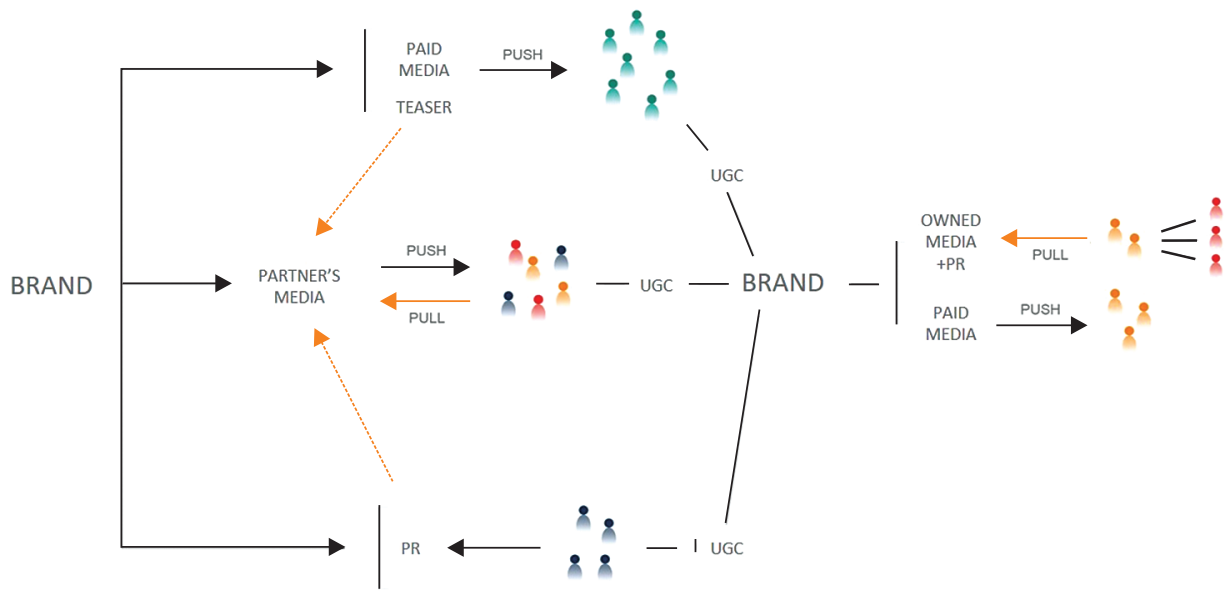

Figure 5.

Communication diagram of the campaign "Sprite. Let the truth refresh you" [the author's study]

In contrast with traditional advertising campaigns in the "old media" where brands exert a total control over the content, in case of projects focused on the participation of recipients, the level of control depends on the nature of the content, its place of publication and method of selling it. In case of campaigns whose main field 
of exploitation is television, the brand exerts total control over the content in the medium of original circulation. This control is being limited along with the flow of contents to subsequent media and engagement of recipients. In case of campaigns originating on the internet, brands control the content only until it is published on a web platform. Following that, they do not influence the manner in which the content spreads or which contexts it interacts with. Erroneous creative and business decisions (including with respect to the abuse of crowdsourcing processes, mentioned in the analysis of the Sprite brand campaign), ignorance of recipients or the nature of the medium, can make this democratization of the dialogue take a turn that is undesirable by the brand, and even lead to an image crisis. In this sense, consumers have the control over the "communication environment" of brands and exert "unrestrained" power over them on the web [cf. Rust, Oliver 1994; Turow 2009; Serazio 2013], which demonstrates that it is difficult to apply a dualistic logic to these processes. The utopian perspective of Jenkins concerning the users' power exerted through media did not fully stack up, but it is hard to say that the situation is unambiguous with respect to it. The processes analysed by me also demonstrate that, although a critical perspective is extremely important, it cannot be reduced to the tension between treating the media as means of consumer expression and the vision of advertisement exclusively as a tool of manipulation.

\section{Biblioggraphy}

Andrejevic M., (2003), Reality TV. The Work of Being Watched, Lanham: Rowman \& Littlefield Publishers, Inc.

Andrejevic M. (2007), iSpy: Surveillance and Power in the Interactive Era, Kansas: University Press of Kansas.

Brabham D.C., (2010), Moving the Crowd at Threadless: Motivations for participation in a crowdsourcing application, "Information, Communication \& Society", 13(8), London: Routledge, p. $1122-1145$.

Brandfolder.com (2015), Million-Dollar Branding Mistakes From Fubu, Pepsi and More, retrieved from: brandfolder.com/blog/biggest-branding-mistakes [access: 9.01.2019].

Bruns A, (2008), The Future Is User-Led: The Path towards Widespread Produsage, "Fibreculture Journal" (11), Perth: Fibrerculture Publications, no pages given.

Caldwell J., (2008), Production Culture: Industrial Reflexivity and Critical Practice in Film and Television, Durham: Duke University Press.

Caldwell J. (2011), Worker Blowback. User-Generated, Worker-Generated and Producer-Generated Content within Collapsing Production Workflows, [in:] J. Bennett, N. Strange (eds.), Television as Digital Media, Durham-London: Duke University Press.

Dijck J. van (2011), Telewizja 2.0: YouTube i narodziny nadawania domowego [homecasting], [w:] T. Bielak, M. Filiciak, G. Ptaszek (red.), Zmierzch telewizji. Przemiany medium. Antologia, Warszawa: Scholar, p. 313-340. 
Edelman D, Salsberg B, (2010), Beyond Paid Media: Marketing's New Vocabulary, „McKinsey Quarterly", New York: McKinsay \& Company.

Idsgn.org (2010), Gap turns to crowdsourcing (or not), retrieved from idsgn.org/posts/gapturns-to-crowdsourcing [access: 23.03.2019].

Jenkins H. (2007), Kultura konwergencji. Zderzenie starych i nowych mediów, przeł. M. Bernatowicz, M. Filiciak, Warszawa: Wydawnictwa Akademickie i Profesjonalne.

Kasprzycki-Rosikon J. (2016, January 18), Personal Interview, Warsaw.

Kopeć K. (2014), Empowerment czy wyzysk? O niejednoznacznej naturze prosumpcji w sieci, „Kultura i Polityka”, nr 16, Cracow: Wyższa Szkoła Europejska im. ks. Józefa Tishnera, p. $158-170$.

Malinowski B. (2015), Wykorzystanie crowdsourcingu i Otwartej Innowacji na przykładzie platformy internetowej My Starbucks Idea, [in:] W. Grzegorczyk (red.), Wybrane problemy zarzq̨dzania i finansów. Studia przypadków, Łódź: Uniwersytet Łódzki, p. 45-54.

Pawian Pictures, (2016, January 24), Personal Interview, Warsaw.

Rust R.T., Oliver R.W. (1994), The Death of Advertising, „Journal of Advertising”, no 23 (4), Abingdon: Taylor \& Francis, Ltd., p. 71-77.

Turow J. (2009), Advertisers and Audience Autonomy at The End of Television [w:] J. Turow, M.P McCallister (eds.), The Advertising and Consumer Culture Reader, Routledge: New York, 402-409.

Turow J. (2014), Media Today: Mass Communication in a Converging World, Routledge: London-New York.

Schäfer M.T. (2011), Bastard Culture! How User Participation Transforms Cultural Production, Amsterdam University Press: Amsterdam.

Schäfer M.T. (2009), Participation Inside? User Activities between Design and Appropriation, [w:] M. van den Boomen, S. Lammes, A.S. Lehmann, J. Raessens, M.T. Schäfer (eds.), Digital Material Tracing New Media in Everyday Life and Technology, Amsterdam University Press: Amsterdam, p. 147-158.

Serazio M. (2013), Your Ad Here. The Cool Sell of Guerrilla Marketing, New York University Press: New York.

Slezkin M. (2016), Zarzadzanie procesem w projektach crowdsourcingowych, www.linkedin.com/ pulse/zarz $\%$ C4\% 85 dzanie-procesem-w-projektach-crowdsourcingowych-micha $\%$ C5\% 82 slezkin?trk=hp-feed-article-title-publish [access: 8.03.2016]. 